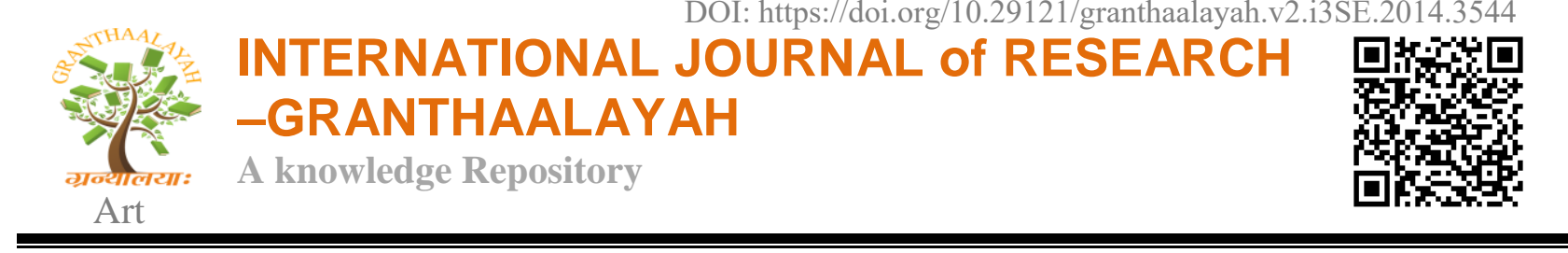

\title{
EMOTIONAL EFECTS OF COLOURS ON LIFE
}

Ekta Sharma Stayasai School Indore

The " Rose Of Temperament " compiled by Goethe \& Schiller in 1798/99. The diagram matches 12 colors to human occupations on their character traits, grouped in four temperaments:

CHOLERIC (red/orange/yellow) ; tyrants ,heroes , adventures.

SANGUINE (yellow/green/cyan); hedonists ,lovers,poets.

PHLEGMATIC (cyan/blue/violet) ;public speakers, historians,teachers.

MELANCHOLIC (VIOLET/MAGENTA/RED) ; philosophers,pedants,rulers.

Color psychology is the study of colors as a determinant of human behavior. Color play a vital role in our in our mood swings. Every color has a unique effects on individuals and stimulates various responses. Take a minute $\&$ imagine the world around you without colors, how boring and unexciting life would be. We are influenced by color in every aspect of our life. Kenneth Fehrman ,co-author of the bok COLOR ; says that "Most people are unaware of the profound effect color has on the behavior.".

Effects of different colors on Humans Emotions :-RED - The color red is the most vibrant of all colors. It stimulates the adrenal glands and the neurons. It is ideal to wear for exercise as it is an invigorating color. The color red symbolizes love;it stimulates heart beat and breathing . However ,too much exposure to red can cause stress;it may also cause frustration and provoke anger. " If one says 'RED' -the name of color -and there are fifty people all will expecting different fifty reds in their mind. " Josef Albers.

YELLOW - Have you ever wondered why smiley is yellow? The reason is that yellow color helps to release a chemical in the brain called Serotonin, essential for causing a happy mood. " Studies have proven that yellow color enhances the concentration and gives the brain \& nervous system a wake-up call ". Too much yellow can cause fatigue. Studies shows that babies cry more in yellow rooms. It is also beneficial for speeding up metabolism and is a common food color." Yellow is capable of charming God. " - Vincent Van Gogh

BLUE - If you want some creative juices spilling out of your mind then get it exposed to color Blue .It helps to produce some calming chemicals in the brain.Blue is used a lot in corporate sector as it denotes loyalty." Blue color is everlastingly appointed by the deity to be a source of delight ."- John Ruskin

BLACK - Black signifies power and authority,it represents knowledge and intelligence. It is the most popular color in the fashion industry because of its association with style and it makes 


\section{INTERNATIONAL JOURNAL Of RESEARCH -GRANTHAALAYAH \\ A knowledge Repository}

Art

people wearing look thin. Black is the most aggressive color ; studies found that hockey teams wearing black jerseys were penalized more for fouls." I've been 40 years discovering that the queen of all colors is black." - Pierre-Auguste Renior

GREEN - Green respects nature and currently it is the most popular color that is being used in interior decoration. The reason is its soothing effect on eyes.Green gives a relaxes the body and alleviates stress.Researchers have proven that the color improves vision.Thats why the class room board is in green color.Green has healing \& hygienic effect and for this it is used a lot in hospitals ." Green how I want you green.Green wind. Green branches."-Federico Garcia Lorca

WHITE - White is considered to be the most neutral color.Baby products usually comes in white to symbolize innocence and cleanliness. White is used by doctors \& nurses to show sterility. A research showed that people having hand tremors didn't shake much in white rooms proving that the color has a calming effect. " White covers a multitude of sins."- Jonathan Milne

ORANGE - Something you need to turn up your bad mood ? Orange is the color for you. As it is derived from red \& yellow it has combining effect of two colors. It stimulates mental abilities and is an ideal color to wear for exams ." Orange is the happiest color" - Frank Sinatra

PURPLE - Purple color symbolizes royalty ,luxury and sophistication.People wearing purple color are perceived to be wealthy. It develops spirituality and deep thoughts Purple color has also been found helpful to intensify sexual activity.

\section{REFERENCES :-}

$1 \quad$ Whitfield, T.W.A., \&Wiltshire,T.J.(1990).

2 Attrill, M. ;Gresty,K. ; Hill,R. ; Barton,R.(2008). 